\title{
Home treatment in Bradford
}

\author{
Patrick Bracken and Bruce Cohen
}

\begin{abstract}
Aims and method We describe a new home treatment service established in one sector of the city of Bradford.

Results There was a tendency for the patients hospltalised from this sector to have more unstable housing backgrounds. It was found that a higher percentage of patients with diagnoses of serious mental illness were cared for at home.

Clinical implications $W e$ argue that, even in the presence of home treatment, there is a continuing need for asylum. However, we make the case that this does not always have to be provided in a medical environment.
\end{abstract}

At present, very high bed occupancy rates are being reported in many parts of the country. This is particularly the case in inner city areas. Health Trusts are being faced with a demand for more acute psychiatric places and, although building more hospital wards is one option, other possibilities are now available. There is a good deal of evidence that many people suffering from acute and severe mental health problems can be cared for successfully in non-institutional settings (Phelan et al, 1996). Indeed, a number of studies from the USA. Australia and Britain have shown improved outcomes with non-hospital-treated groups in terms of: symptoms and social functioning (Marks et al, 1994); probability of subsequent employment (Stein et al, 1975): improved patient and relative satisfaction (Hoult \& Reynolds, 1984; Dean et al, 1993); and independent living arrangements and staying in education (Mosher \& Menn, 1978). In addition, there is evidence that non-hospital treatment is less expensive than in-patient care (Fenton et al, 1982) and more cost-effective in the longer term (Knapp et al, 1998).

However, it has been reported also that many of these gains can be lost over time (Test, 1990; Marks et al. 1994). In a number of studies it was found that patients still needed help with disabilities, many continued to be anxious, depressed and inactive, only a minority held paid jobs, lived with relatives and needed no medication, and unexpected suicides and antisocial behaviour still occurred (see Leff, 1991; Thornicroft \& Breakey, 1991; Marks, 1992). Marks et al (1994) have remarked that careful training and clinical audit are needed if gains are to be sustained over time.
Increasingly, the concept of home treatment has become popular in Britain and a number of teams have been established in different parts of the country (Dean \& Gadd, 1990; Muijen et al. 1992). Although there are many different forms of 'home treatment' in existence, this term is generally taken to refer to services that provide intensive support and out-of-hours availability. Many services operate on a 24-hour basis. However, home treatment services differ greatly in terms of their resources, philosophies of care and relationships with other mental health services. In a survey of crisis services in England, including home treatment projects. Hogan et al (1997) comment that there are a very large number of different types of service in operation and that many do not endure over time. It has been noted also that many new communitybased services have been established as 'demonstration projects' with high levels of resources and staff. This makes it difficult to generalise results to other sites (Thomas et al, 1996). In its report entitled Finding a Place, the Audit Commission identified the vicious circle in which it is difficult to develop community services because of the pressure on hospital beds, which is where most health service resources are located (Audit Commission, 1994). However, they state that "all authorities should be planning how they are to break this vicious circle".

\section{Home treatment in Bradford}

Bradford is a city with a large immigrant population and very high levels of social deprivation. The local psychiatric in-patient unit at Lynfield Mount has 84 acute beds (including places for substance misuse patients) and serves a population of 380000 . Bed occupancy rates have been extremely high and in the past 10 years it has been felt that there was a need to develop more acute services. In addition, there is a very active 'user movement' in Bradford and there have been calls for alternative forms of acute provision and the development of crisis services in the city (Bailey, 1994). In 1995 a decision was made by the provider trust, social services and the health authority to expand acute provision by developing a home treatment service. By the following year, the service was operational. 
The team is multi-disciplinary and provides input on a 24-hour, seven days a week basis. Medical input is currently from a full-time clinical medical officer with support from the sector consultant. The decision to admit patients or to refer to home treatment is made by the sector consultant during normal working hours and by the duty consultant out of hours. However, this is always something that is negotiated between professionals, patients and carers and influenced by clinical and social factors and by questions of risk. Patients are visited as often as necessary, sometimes two to three times per day. Regular contact by telephone is established and, if needed, patients are given the use of a mobile phone for the length of their stay on home treatment.

A key element of the Bradford service has been its orientation towards a 'user perspective'. A post of 'Service User Development Worker' was established early on. This person is an ex-patient of the psychiatric services and has been active in local campaigning groups. He is a full member of the team and his work includes encouraging the active involvement of patients and their families with the team and also ensuring that the practice of the team is genuinely sensitive to their needs.

Initially the service was targeted at the Ashgrove sector, the largest catchment area in Bradford, which covers the south-west of the city and the city centre. For a short period early in 1997 the service ran on a city-wide basis. It has now been reorganised to cover Ashgrove and one neighbouring sector and thus is effectively available across half of the city. Like many other parts of the country, Bradford has had difficulties with consultant recruitment and the Ashgrove sector was served by a series of locums from June 1996 to June 1997. As discussed below, this had a negative effect on the development of the new service.

In this paper we compare patients cared for by home treatment with those admitted to hospital in the initial period of operations (22 March 1996-12 November 1996). Data for this comparison were obtained by using a pre-designed monitoring form that was filled in by junior medical staff at the hospital and by the home treatment team and included demographic, socio-economic and medical details for each patient. Only patients who were admitted and discharged during this time period were included. All the patients who were admitted prior to 22 March 1996 were discharged before 12 November 1996.

\section{Findings}

In 1996, the year in which home treatment began, there were 110 admissions from the sector. This represented a $25 \%$ drop compared with the previous year. No reduction in admissions was observed in neighbouring sectors. The impact of home treatment was seen most clearly between April and July 1996, when admissions to hospital for the sector reached the lowest on record. Admissions to hospital increased from August 1996, probably due to the departure of the original sector consultant and the arrival of temporary locums.

During the period in which monitoring forms were completed, 53 people were admitted to home treatment and 63 were admitted to hospital. There were no significant differences in the demographic characteristics of patients who were referred to home treatment and those referred to hospital. Age and gender characteristics were very similar. Twenty per cent (10) of the home treatment patients were from ethnic minorities, compared with $17 \%$ (10) of those admitted to hospital.

A sizeable (but not statistically significant) difference was found in the housing tenure of those admitted to home treatment. Forty-three per cent (23) lived in owner-occupied accommodation, compared with $22 \%$ (11) of the hospital group. Home treatment patients were less likely to be in housing association accommodation, temporary hostels or homeless. There were no significant differences between the two groups with regard to whether they lived on their own or not, nor with regard to their employment status.

Sixty-seven per cent of the patients on home treatment, compared with $38 \%$ of the people admitted to hospital, were already on the Care Programme Approach $\left(\chi^{2}=11.1\right.$, d.f. $\left.=2, P<0.01\right)$. Eighteen per cent of both groups were admitted on a section of the Mental Health Act in their last admission. Significant differences in terms of diagnosis were found between the two groups $\left(\chi^{2}=13.6\right.$, d.f. $\left.=4, P<0.01\right)$. Sixty-six per cent of home treatment patients had a diagnosis of either schizophrenia or manic depression, compared with only $38 \%$ of those admitted. Similar numbers were treated at home and in hospital with diagnoses of depression or anxiety disorders. A substantial number of patients admitted to hospital had primary diagnoses of personality disorder or drug/alcohol problems $(37 \%$, compared with only $12 \%$ of those on home treatment).

On average, admissions to home treatment were of longer duration than admissions to hospital: 35.2 days and 17.1 days, respectively. However, the tendency for more patients with diagnoses in the 'severe mental illness' category to be looked after by home treatment goes some way to explaining this. Of those on home treatment longer than 29 days, $73 \%$ (19) had a diagnosis of schizophrenia or manic-depressive disorder. 
During the time period covered, $11 \%$ (six) of the home treatment patients were admitted to hospital; one-third of these (two) were detained under a section and were hypomanic; two were admitted due to the carer's inability to cope; one was admitted because of severe confusion after having electroconvulsive therapy; and another needed detoxification from alcohol.

\section{Discussion}

Mental health services in Bradford operate with a relatively small bed to population ratio: 22 per 100000 population. Although it is impossible to predict, at this stage, what the longer term impact of home treatment on bed usage will be, the service has eased pressure on the in-patient unit and has proved to be a safe and effective alternative to hospital.

However, a number of difficulties were experienced in the establishment of this service. The greatest was the problem with locum consultant cover of the catchment area in question. This meant that fewer patients were referred to the service than could have been, because these doctors were unfamiliar with the service and its operational policy. As mentioned above, this problem has now been resolved and a permanent consultant has been appointed. However, it highlights the need to integrate home treatment with other service elements so that changes in personnel do not affect the service so seriously. Similar difficulties have been found elsewhere and conflicts have arisen around the 'ownership' of patients and the nature of appropriate medical interventions (see Audini et al, 1994). In our opinion, home treatment teams should not be 'tagged on' to already existing services but should be designed not only to provide intensive support in times of crisis but also to function as 'gate-keepers' with regard to other supports, including hospital admission.

Although the decision to refer to home treatment or to hospital, during the period of this study, was ultimately in the hands of the sector consultant, patient factors obviously played a large role in these decisions. The trend was towards admission of patients in poorer housing situations. Contrary to expectation, there was a significant tendency for more patients with 'severe mental illness' to be cared for by the home treatment team. On the other hand, more patients with personality disorders or drug and alcohol problems were admitted to hospital. Often, such patients insisted on admission even though the professionals involved were doubtful about the benefits of hospitalisation.

These results would appear to question our usual understanding of the role of the acute psychiatric unit as catering for patients who are 'more ill'. While places of genuine asylum are obviously still in demand for people undergoing crises of different types, the question to be asked is: do these places really need to be hospitals? We do not think so. We believe that home treatment can provide a real alternative to hospital admission for very many patients. However, it needs to operate in conjunction with a range of services that provide supported accommodation in times of crisis.

\section{References}

AUdin, B., MARKS, I. M., LAWRENCE, R. E.. et al (1994) Homebased versus out-patient/in-patient care for people with serious mental illness. Phase II of a controlled study. British Joumal of Psychiatry. 166, 204-210.

AudrT Commission (1994) Finding a Place: a Review of Mental Health Services for Adults. London: HMSO.

BAILEY. S. (1994) Bradford crisis services: where are they? Open Mind, 72, 15.

DEAN, C. \& GADD, E. M. (1990) Home treatment for acute psychiatric illness. British Medical Joumal, $\mathbf{3 0 1}$. 1021-1023.

-. Philups, J., GADD, E. M., et al (1993) Comparison of community based service with hospital based service for people with acute, severe psychiatric illness. British Medical Journal, so7, 473-476.

Fenton, F. R., Tessier, L., Contandriopoulos, A. P., et al (1982) A comparative trial of home and hospital psychiatric treatment: financial costs. Canadian Journal of Psychiatry. 27. 177-187.

HOGAN, K., CRAWFORD-WRIGHT, A., ORME, S., et al (1997) Walsall Crisis Support Service Final Report, Volume 2: Literature Review, Wolverhampton: University of Wolverhampton.

Hoult, J. \& ReYNolds, I. (1984) Schizophrenia: a comparative trial of community orientated and hospital orientated psychiatric care. Acta Psychiatrica Scandinavica, 69, 359-372.

KNAPP, M.. MARKS, I.. WOLSTENHOLME. J., et al (1998) Homebased versus hospital-based care for serious mental illness. Controlled cost-effectiveness study over four years. British Joumal of Psychiatry. 172. 506-512.

LEFF. J. (1991) Evaluation of the closure of a mental hospital. In The Closure of Mental Hospitals (eds P. Hall \& I. F. Brockington), pp. 25-32. London: Gaskell.

MARKS. I. M. (1992) Innovations in mental health care delivery. British Journal of Psychiatry. 160. 589-597.

-. Connolly, J., Mulven, M.. et al (1994) Home-based versus hospital-based care for people with serious mental illness. British Journal of Psychiatry. 166. 179-194.

MOSHER. L. R. \& MENN, A. Z. (1978) Community residential treatment for schizophrenia: two-year follow-up. Hospital and Community Psychiatry. 29. 715-723.

MuWEN, M.. MARKS, I.. CONNOLLY. J., et al (1992) Home based care and standard hospital care for patients with severe mental illness: a randomised control trial. British Medical Journal, s04. 749-754.

Phelan, M.. STRATHDEe, G. \& Thornicroft, G. (1996) Emergency Mental Health Services in the Community. Cambridge: Cambridge Untversity Press.

STEIN. L.. TEST, M. A. \& MARX. A. J. (1975) Alternative to the hospital: a controlled study. American Journal of Psychiatry. 132, 517-521. 
TEST. M. A. (1990) Theoretical and research bases of community care programmes. In Mental Health Care Delivery: Innovations, Impediments and Implementations (eds I. M. Marks \& R. Scott). Cambridge: Cambridge University Press.

Thomas, P., Greenwood, M., Kearney, G., et al (1996) The first twelve months of a community support bed unit. Psychiatric Bulletin, 20, 455-458.

THORNICROFT, G. \& BREAKEY, W. (1991) The COSTAR Program 1: Improving patients' networks. British Journal of Psychiatry. 169, 245-249.
*Patrick Bracken, Senior Research Fellow and Consultant Psychiatrist; and Bruce Cohen, Research Fellow, Department of Social and Economic Studies, University of Bradford, Bradford BD7 1DP

*Correspondence

\title{
A dedicated district poisons treatment unit: response to the College guidance on the management of deliberate self-harm
}

\author{
R. C. Scorer, P. Beck, J. Bisson, S. White and P. A. Routledge
}

Alms and method An examination of the activities of a district-wide dedicated admission unit for poisoned patients in Cardiff, Wales, between 1987 and 1997. Number of admission episodes, gender, drugs taken, intent, psychiatric diagnosis and disposal were recorded.

Results Although the number of admission episodes almost doubled over the 10-year period, the median length of stay fell by almost half.

Clinical implications the results suggest that a dedicated unit is a cost-effective model for the management of poisoned patients.

As a result of the College report on the management of deliberate self-harm, a six-bedded dedicated poisons treatment unit ward was opened in 1986 to serve the population of South Glamorgan (now Southern Bro Taf). Over the last 10 years, the number of admission episodes has almost doubled from 933 to 1588 . However, having a single centre in a city or district facilitates rapid psychiatric or social evaluation. and the average length of stay has fallen from 34 to 18 hours over the same period, so that no extra beds have been necessary. A dedicated unit has ensured that nurses dealing with such patients have psychiatric nursing experience and that medical, nursing and social work staff can receive regular in-service training in the management of deliberate self-poisoning. We also hope that the increased opportunities afforded for research will help in the prevention of poisoning and in developing more effective patterns of care for patients who have deliberately harmed themselves.

\section{The study}

In 1983, a multi-professional working party was set up by the Royal College of Psychiatrists at the request of the Department of Health and Social Security (DHSS). Its recommendations were approved by the College's Council in June 1983 and published in the Bulletin of the Royal College of Psychiatrists in November of the same year (Royal College of Psychiatrists, 1983). One important recommendation in this report was that patients should be admitted to one or two designated medical wards, to special beds in a short-stay ward or to a poisoning treatment 